\title{
Skin Temperature Changes in Patients With Unilateral Lumbosacral Radiculopathy
}

\author{
Jong Yun Ra, $\mathrm{MD}^{1}$, Sun An, MD${ }^{1}$, Geun-Ho Lee, $\mathrm{MD}^{2}$, Tae Uk Kim, MD ${ }^{1}$, \\ Seong Jae Lee, $\mathrm{MD}^{1}$, Jung Keun Hyun, $\mathrm{MD}^{1,3,4}$
}

Departments of ${ }^{1}$ Rehabilitation Medicine and ${ }^{2}$ Neurology, Dankook University College of Medicine, Cheonan; ${ }^{3}$ WCU Research Center of Nanobiomedical Science, ${ }^{4}$ Institute of Tissue Regeneration Engineering, Dankook University, Cheonan, Korea

Objective To clarify the relationship of skin temperature changes to clinical, radiologic, and electrophysiological findings in unilateral lumbosacral radiculopathy and to delineate the possible temperature-change mechanisms involved.

Methods One hundred and one patients who had clinical symptoms and for whom there were physical findings suggestive or indicative of unilateral lumbosacral radiculopathy, along with 27 normal controls, were selected for the study, and the thermal-pattern results of digital infrared thermographic imaging (DITI) performed on the back and lower extremities were analyzed. Local temperatures were assessed by comparing the mean temperature differences $(\Delta \mathrm{T})$ in 30 regions of interest (ROIs), and abnormal thermal patterns were divided into seven regions. To aid the diagnosis of radiculopathy, magnetic resonance imaging (MRI) and electrophysiological tests were also carried out.

Results The incidence of disc herniation on MRI was $86 \%$; $43 \%$ of patients showed electrophysiological abnormalities. On DITI, $97 \%$ of the patients showed abnormal $\Delta \mathrm{T}$ in at least one of the 30 ROIs, and $79 \%$ showed hypothermia on the involved side. Seventy-eight percent of the patients also showed abnormal thermal patterns in at least one of the seven regions. Patients who had motor weakness or lateral-type disc herniation showed some correlations with abnormal DITI findings. However, neither pain severity nor other physical or electrophysiological findings were related to the DITI findings.

Conclusion Skin temperature change following lumbosacral radiculopathy was related to some clinical and MRI findings, suggesting muscle atrophy. DITI, despite its limitations, might be useful as a complementary tool in the diagnosis of unilateral lumbosacral radiculopathy.

Keywords Radiculopathy, Thermography, Magnetic resonance imaging, Electrodiagnosis, Muscle atrophy

Received August 16, 2012; Accepted November 15, 2012

Corresponding author: Jung Keun Hyun

WCU Research Center of Nanobiomedical Science, Dankook University, 119 Dandae-ro, Dongnam-gu, Cheonan 330-714, Korea

Tel: +82-41-550-6640, Fax: +82-41-551-7062, E-mail: rhhyun@dankook.ac.kr

@ This is an open-access article distributed under the terms of the Creative Commons Attribution Non-Commercial License (http://creativecommons. org/licenses/by-nc/3.0) which permits unrestricted noncommercial use, distribution, and reproduction in any medium, provided the original work is properly cited.

Copyright $\odot 2013$ by Korean Academy of Rehabilitation Medicine

\section{INTRODUCTION}

Physical examination, magnetic resonance imaging (MRI), and electrophysiological tests are the usual tools for diagnosis of lumbosacral radiculopathy in the clinical setting. Accurate diagnosis of patients suspected of having radiculopathy requires a physical examination for the typical clinical signs, which include sensory deficits, 
muscle weakness and impaired deep tendon reflexes in the lower extremities. However, the diagnostic value of each of these findings is poor [1] as normal physical examination does not rule out surgical findings of radiculopathy [2]. MRI can detect lumbosacral disc herniation (the most common cause of lumbosacral radiculopathy), and indeed it provides superior image quality for spine and intervertebral discs compared to computed tomography (CT). Nonetheless, MRI is more expensive than $\mathrm{CT}$, and some researchers also have found that MRI has limitations with respect to the diagnosis of low back pain or radiculopathy [3-5]. Tellingly, a considerable number of patients and even asymptomatic subjects have been misdiagnosed with disc herniation by MRI $[6,7]$. MRI moreover has low sensitivity, shows poor correlation with clinical findings, and is not an entirely suitable tool in the formulation of conservative management plans for patients with low back pain and radiculopathy [3]. Alternatively, electrophysiological testing is a useful diagnostic tool for evaluation of lumbosacral root involvement following disc herniation [8]. Among those tools, needle electromyography is the most widely accepted [9]. However, electrical stimulation and needle insertion cause discomfort in patients, and needle electromyography shows positive findings only in severe cases [8].

Digital infrared thermographic imaging (DITI) detects skin temperature distribution noninvasively, and offers a convenient method of evaluation in the clinical setting [10]. DITI can effectively assess sympathetic dysfunction such as complex regional pain syndrome, as well as circulatory dysfunction in diabetes mellitus patients $[11,12]$. Some researchers have reported skin temperature changes following cervical disc herniation $[13,14]$, although the relationship between skin temperature and low back pain [15], radiating pain [16] or lumbar disc herniation [17] is not obvious. In two of our previous studies, we found skin temperature decrements following shoulder impingement syndrome and unilateral ulnar neuropathy, and these results might reflect atrophy of the involved muscles $[18,19]$. This suggests that muscle atrophy in the back or lower extremities following lumbosacral radiculopathy might affect skin temperature.

In this study, we aimed to clarify the relationship of skin temperature changes to clinical, MRI and electrophysiological findings in unilateral lumbosacral radiculopathy, and to delineate the possible temperature-change mechanisms involved.

\section{MATERIALS AND METHODS}

\section{Participants}

One hundred and one patients (59 males and $42 \mathrm{fe}$ males; mean age, 45.8 years) who had clinical symptoms and for whom there were physical findings suggestive or indicative of unilateral lumbosacral radiculopathy were selected as participants in the study. The symptoms were radiating pain and/or numbness in the lower leg, and the physical findings were decreased sensation and/or weakness in the lower leg. Patients who had bilateral symptoms or signs, a history of fracture or surgery on the spine or lower legs, inflammatory skin lesions, peripheral polyneuropathy or plexopathy were excluded. The interval from symptom onset to the DITI study was 208 days (Table 1). We additionally evaluated 27 adults (18 males and 9 females; mean age, 27.4 years) without clinical signs suggestive of lumbosacral radiculopathy. This study was approved by the Institutional Review Board of Dankook University (DKU0904-033).

\section{Methods}

\section{Clinical assessments}

All of the patients were assessed for pain severity, and underwent sensory, muscle and deep tendon reflex tests when DITI was performed. We checked for radiating pain that involved the lower extremity, and measured the pain severity on a visual analog scale. Deficit in light touch sense and muscle weakness of the lower extremity were classified from L4 to S1, according to the dermatome and myotome involved, respectively. Decreased knee or ankle reflexes were considered an abnormality at the L5 or S1 root level, respectively.

\section{MRI}

We performed MRI on the lumbosacral region of $69 \mathrm{pa}-$

Table 1. Subjects' characteristics

\begin{tabular}{lcc}
\hline \multicolumn{1}{c}{ Variable } & $\begin{array}{c}\text { Controls } \\
(\mathbf{n = 2 7})\end{array}$ & $\begin{array}{c}\text { Patients } \\
(\mathbf{n = 1 0 1 )}\end{array}$ \\
\hline Male:female & $18: 9$ & $59: 42$ \\
Age (yr) & $27.4 \pm 2.5$ & $45.8 \pm 14.7^{*}$ \\
\hline Involved side (right:left) & - & $39: 62$ \\
Symptom duration (day) & - & $208.0 \pm 367.3$ \\
\hline
\end{tabular}

Values are presented as mean \pm standard deviation. ${ }^{*} \mathrm{p}<0.05$ by independent $\mathrm{t}$-test. 
tients using the 1.5 Tesla MRI system Genesis-Signa Twin Speed (GE Medical Systems, Milwaukee, WI, USA), and T1- and T2-weighted axial and sagittal images were used in the analysis. The criterion for an abnormal finding was disc protrusion, including disc extrusion and sequestration in the L3-4, L4-5 or L5-S1 level, as diagnosed by a radiologist specializing in spine and musculoskeletal radiology. The location of disc protrusion was classified as one of two types: central or lateral.

\section{Electrophysiological testing}

Seventy-four patients also underwent electrophysiological tests. We conducted sensory nerve conduction studies (NCSs) on both superficial peroneal and sural nerves, as well as motor NCSs on both tibial and peroneal nerves, to exclude peripheral neuropathies. Somatosensory evoked potentials (SEPs) were obtained following stimulation of the sural nerve, superficial peroneal nerve and posterior tibial nerve, and Hoffman's reflex test and needle electromyography were performed on the mus- cles of the back and involved lower legs. The criteria for unilateral radiculopathy were delay (latency difference $>3 \mathrm{~ms}$ ) or absence of the P1 latency of one or more SEPs on the involved side [20], and abnormal spontaneous activities at rest in the unilateral multifidus muscles and/or involved lower limb muscles. For patients with unilateral S1 radiculopathy, a latency difference of Hoffmann reflex exceeding $1.0 \mathrm{~ms}$ between the involved and uninvolved sides, was considered abnormal [21].

\section{DITI}

All of the patients and controls underwent DITI. The DITI device employed was the IRIS-5000 (Medicore, Seoul, Korea), which consists of an infrared camera, a computer, and an LCD monitor. The device detected emitted infrared energy from the body surface and then divided the thermal differences into 16 color levels, using pixels. The temperature within the DITI room was maintained at a constant level, within the $19^{\circ} \mathrm{C}-21^{\circ} \mathrm{C}$ range; the patients waited with no clothing on their back
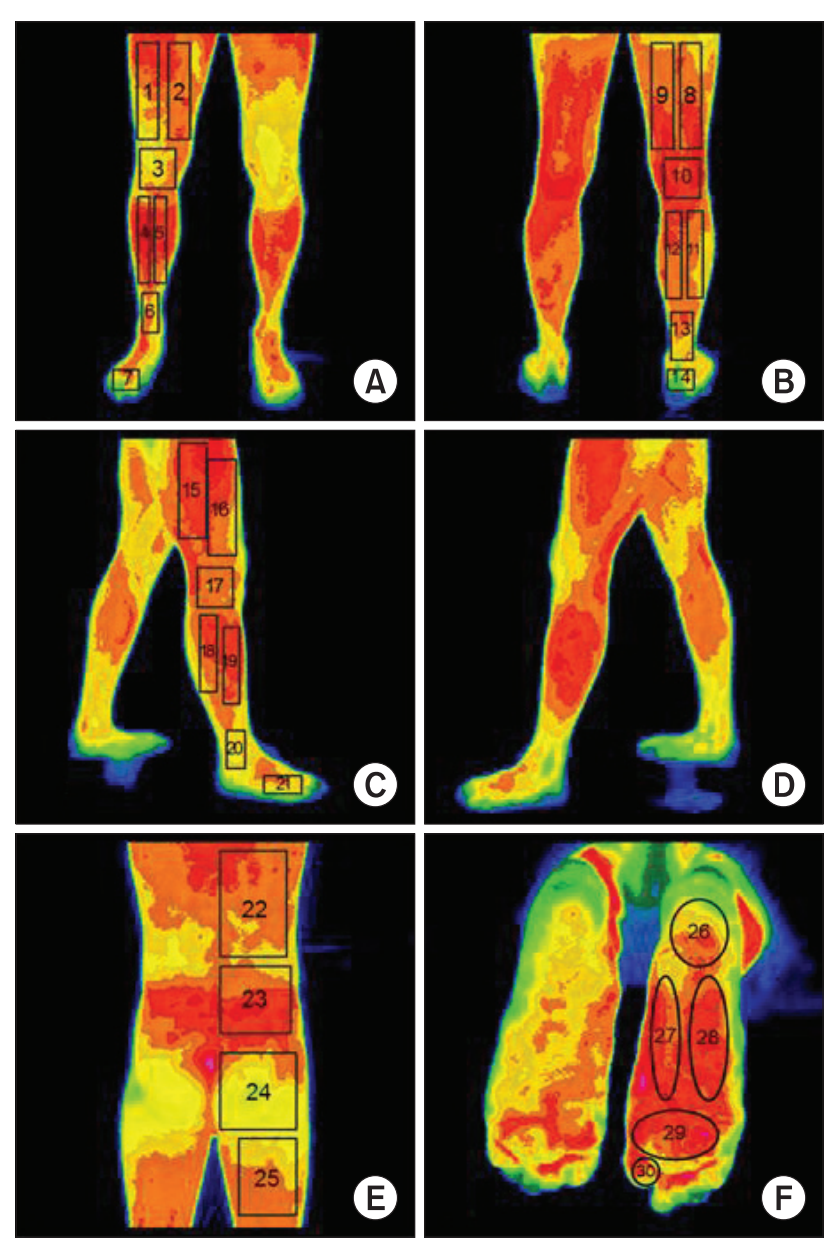

ROI

1. Anterolateral thigh

2. Anteromedial thigh

3. Anterior knee

4. Anterolateral calf

5. Anteromedial calf

6. Anterior ankle

7. Anterior foot

8. Posterolateral thigh

9. Posteromedial thigh

10. Posterior knee

11. Posterolateral calf

12. Posteromedial calf

13. Posterior ankle

14. Heel

15. Lateroposterior thigh

16. Lateroanterior thigh

17. Lateral knee

18. Lateroposterior calf

19. Lateroanterior calf

20. Lateral ankle

21. Lateral foot

22. Middle back

23. Low back

24. Buttock

25. Posterior thigh

26. Posterior plantar

27. Medial plantar

28. Lateral plantar

29. Anterior plantar

30. First toe
Fig. 1. Determination of 30 regions of interest (ROIs) detected by digital infrared thermographic imaging. (A) anterior view, (B) posterior view, (C) right lateral view of lower extremities, (D) left lateral view of lower extremities, (E) posterior view of back, and (F) plantar view. 
or lower extremities for 15 minutes prior to the DITI. The DITI was performed on the back and lower extremities in six views: the posterior view of the back, the anterior, posterior, and right and left lateral views of the lower extremities, and the plantar view. The results were analyzed by evaluating the localized temperature difference in 30 regions of interest (ROIs) from the back to the plantar surface (Fig. 1). In the anterior view of the lower extremities, the ROIs were anterolateral thigh (ALT), anteromedial thigh (AMT), anterior knee (AK), anterolateral calf (ALC), anteromedial calf (AMC), anterior ankle (AA), and anterior foot (AF); in the posterior view of the lower extremities, they were posterolateral thigh (PLT), posteromedial thigh (PMT), posterior knee (PK), posterolateral calf (PLC), posteromedial calf (PMC), posterior ankle (PA), and heel (HE); in the two lateral views of the lower extremities, they were lateroanterior thighs (LAT) and lateroposterior thighs (LPT), lateral knees (LK), lateroanterior calves (LAC), lateroposterior calves (LPC), lateral ankles (LA), and lateral feet (LF); in the posterior view of the back, they were middle back (MB), low back (LB), buttock (BT) and posterior thigh (PT); and in the plantar view, they were posterior plantar (PP), medial plantar (MP), lateral plantar (LP), and anterior plantar (AP) areas, and first toe (FT). In the patients, the temperature difference $(\Delta \mathrm{T})$ in each of the 30 ROIs was determined by subtracting the temperature on the uninvolved side from that on the involved side; in the controls, it was obtained by subtracting the temperature on the right side from that on the left side. An abnormal finding for each ROI was defined as the absolute value of $\Delta \mathrm{T}$ being greater than the summation of the mean absolute value and two standard deviations of $\Delta \mathrm{T}$ in the controls. These abnormal cases were classified into hyperthermic and hypothermic groups. The hyperthermic cases were those in which the temperature on the involved side was higher than on the uninvolved side; the hypothermic cases were those where the temperature on the involved side was lower than on the uninvolved side.

The abnormal thermal patterns were then classified, by dividing the involved area into the following eight surface regions: $\mathrm{LB}, \mathrm{BT}$, thigh, knee, lower leg, ankle, foot, and plantar. An abnormal $\Delta \mathrm{T}$ (i.e., hypothermia or hyperthermia) in more than two ROIs was considered to be an abnormal thermal pattern.

\section{Statistics}

SPSS ver. 15.0 (SPSS Inc., Chicago, IL, USA) was used in the statistical analysis. All data are reported as the mean \pm standard deviation. An independent t-test was performed to compare the control and patient $\Delta \mathrm{T}$ for each ROI, and Fisher exact test was used to delineate the relationship between the DITI findings and the clinical,

Table 2. Clinical findings, MRI, EMG, and DITI findings

\begin{tabular}{|c|c|c|}
\hline Method & Abnormal finding & No. (\%) \\
\hline \multirow{12}{*}{$\begin{array}{l}\text { Clinical findings } \\
(\mathrm{n}=101)\end{array}$} & Lower extremity pain & $63(62)$ \\
\hline & Sensory changes & $84(83)$ \\
\hline & L4 dermatome & $17(17)$ \\
\hline & L5 dermatome & $47(47)$ \\
\hline & S1 dermatome & $38(38)$ \\
\hline & Motor weakness & $43(43)$ \\
\hline & L4 myotome & $7(7)$ \\
\hline & L5 myotome & $33(33)$ \\
\hline & S1 myotome & $21(21)$ \\
\hline & Decreased deep tendon reflex & $20(20)$ \\
\hline & Knee jerk & $13(13)$ \\
\hline & Ankle jerk & $9(9)$ \\
\hline \multirow[t]{7}{*}{ MRI (n=69) } & Protrusion & $59(86)$ \\
\hline & Central type & $21(30)$ \\
\hline & Lateral type & $38(55)$ \\
\hline & Level of protrusion & \\
\hline & L3-4 level & $14(20)$ \\
\hline & L4-5 level & $42(61)$ \\
\hline & L5-S1 level & $37(54)$ \\
\hline \multirow[t]{5}{*}{ EMG $(n=74)$} & All abnormal cases & $32(43)$ \\
\hline & Needle EMG & $22(30)$ \\
\hline & L4 level & $2(3)$ \\
\hline & L5 level & $15(20)$ \\
\hline & S1 level & $11(15)$ \\
\hline \multirow[t]{6}{*}{ DITI (n=101) } & $\begin{array}{l}\text { Abnormal cases in at least one } \\
\text { of } 30 \text { ROIs }\end{array}$ & 98 \\
\hline & Hyperthermia>hypothermia & $18(18)$ \\
\hline & Hyperthermia<hypothermia & $80(79)$ \\
\hline & Abnormal thermal pattern & $79(78)$ \\
\hline & Hyperthermia & $7(7)$ \\
\hline & Hypothermia & $72(71)$ \\
\hline
\end{tabular}

MRI, magnetic resonance imaging; EMG, electromyography; DITI, digital infrared thermographic imaging; ROI, regions of interest. 
MRI and electrophysiological findings. The significance was set at $\mathrm{p}<0.05$.

\section{RESULTS}

\section{Clinical, MRI, and electrophysiological findings}

The most common clinical finding was sensory changes (83\%): radiating pain to the lower extremities was found in $62 \%$ of the patients, and motor weakness and decrement of deep-tendon reflex were found in $43 \%$ and $23 \%$, respectively (Table 2). Disc protrusion in the lumbosa- cral region was found in $86 \%$ of the patients, the lateral type (55\%) predominating over the central type (30\%). Protrusion was prominent at the L4-5 (61\%) and L5-S1 (54\%) levels. Forty-three percent of the patients showed electrophysiological abnormalities, and $30 \%$ also showed needle electromyography abnormalities (Table 2).

\section{DITI findings}

Most of the patients had an abnormal $\Delta \mathrm{T}$ in at least one of the 30 ROIs (97\%), and $78 \%$ of patients showed hypothermic ROIs more than hyperthermic ROIs whereas only

Table 3. Temperature differences in 30 regions of interest (ROIs) for controls and patients

\begin{tabular}{|c|c|c|c|c|}
\hline View & ROI & Control $\left({ }^{\circ} \mathbf{C}\right)$ & Patient $\left({ }^{\circ} \mathbf{C}\right)$ & p-value \\
\hline \multirow[t]{7}{*}{ Anterior view of lower extremities } & Anterolateral thigh & $0.00 \pm 0.18$ & $-0.11 \pm 0.39$ & $0.03^{*}$ \\
\hline & Anteromedial thigh & $0.07 \pm 0.18$ & $-0.12 \pm 0.48$ & $0.001^{*}$ \\
\hline & Anterior knee & $0.09 \pm 0.31$ & $-0.16 \pm 0.71$ & $0.009 *$ \\
\hline & Anterolateral calf & $0.01 \pm 0.28$ & $-0.48 \pm 0.64$ & $0.000^{*}$ \\
\hline & Anteromedial calf & $0.07 \pm 0.32$ & $-0.32 \pm 0.61$ & $0.000^{*}$ \\
\hline & Anterior ankle & $-0.16 \pm 0.31$ & $-0.31 \pm 0.90$ & 0.19 \\
\hline & Anterior foot & $-0.23 \pm 0.38$ & $-0.24 \pm 1.46$ & 0.97 \\
\hline \multirow[t]{7}{*}{ Posterior view of lower extremities } & Posterolateral thigh & $-0.08 \pm 0.19$ & $-0.21 \pm 0.41$ & $0.02^{*}$ \\
\hline & Posteromedial thigh & $-0.08 \pm 0.19$ & $-0.19 \pm 0.42$ & 0.05 \\
\hline & Posterior knee & $-0.01 \pm 0.27$ & $-0.12 \pm 0.43$ & 0.09 \\
\hline & Posterolateral calf & $-0.07 \pm 0.26$ & $-0.40 \pm 0.68$ & $0.000^{*}$ \\
\hline & Posteromedial calf & $-0.02 \pm 0.23$ & $-0.43 \pm 0.60$ & $0.000^{*}$ \\
\hline & Posterior ankle & $0.06 \pm 0.37$ & $-0.34 \pm 0.82$ & $0.000^{*}$ \\
\hline & Heel & $0.04 \pm 0.37$ & $-0.23 \pm 0.83$ & $0.04^{*}$ \\
\hline \multirow[t]{7}{*}{ Lateral view of lower extremities } & Lateroanterior thigh & $0.01 \pm 0.21$ & $-0.26 \pm 0.53$ & $0.000^{*}$ \\
\hline & Lateroposterior thigh & $0.01 \pm 0.27$ & $-0.25 \pm 0.44$ & $0.000^{*}$ \\
\hline & Lateral knee & $-0.05 \pm 0.31$ & $-0.12 \pm 0.57$ & 0.40 \\
\hline & Lateroanterior calf & $0.10 \pm 0.31$ & $-0.55 \pm 0.66$ & $0.000^{*}$ \\
\hline & Lateroposterior calf & $0.04 \pm 0.29$ & $-0.44 \pm 0.64$ & $0.000^{*}$ \\
\hline & Lateral ankle & $0.07 \pm 0.35$ & $-0.38 \pm 0.80$ & $0.000^{*}$ \\
\hline & Lateral foot & $-0.05 \pm 0.32$ & $-0.31 \pm 0.93$ & $0.04^{*}$ \\
\hline \multirow[t]{4}{*}{ Posterior view of back } & Middle back & $-0.06 \pm 0.16$ & $0.04 \pm 0.47$ & 0.08 \\
\hline & Low back & $-0.08 \pm 0.19$ & $0.08 \pm 0.50$ & $0.004^{*}$ \\
\hline & Buttock & $-0.05 \pm 0.21$ & $-0.11 \pm 0.43$ & 0.32 \\
\hline & Posterior thigh & $-0.04 \pm 0.29$ & $-0.06 \pm 0.55$ & 0.76 \\
\hline \multirow[t]{5}{*}{ Plantar view } & Posterior plantar & $0.06 \pm 0.37$ & $-0.39 \pm 0.95$ & $0.000^{*}$ \\
\hline & Medial plantar & $-0.10 \pm 0.37$ & $-0.34 \pm 0.94$ & $0.04^{*}$ \\
\hline & Lateral plantar & $-0.01 \pm 0.50$ & $-0.30 \pm 0.93$ & $0.04^{*}$ \\
\hline & Anterior plantar & $-0.06 \pm 0.50$ & $-0.10 \pm 2.61$ & 0.57 \\
\hline & First toe & $-0.06 \pm 0.60$ & $-0.12 \pm 1.51$ & 0.43 \\
\hline
\end{tabular}

Values are presented as mean \pm standard deviation.

${ }^{*} \mathrm{p}<0.05$ by independent $\mathrm{t}$-test. 
$18 \%$ of patients showed hyperthermic ROIs more (Table 2). Seventy-eight percent of the patients showed abnormal thermal patterns from the low back to the lower extremities (Table 2). When comparing the $\Delta \mathrm{T}$ in the 30 ROIs between the patients and the controls, 20 regions showed differences (Table 3). These regions were, in the anterior view, ALT, AMT, AK, ALC, and AMC; in the posterior view, PLT, PLC, PMC, PA, and HE; in the two lateral views of the lower extremities, LAT, LPT, LAC, LPC, $\mathrm{LA}$, and LF; in the posterior view of the back, LB, and in the plantar view, PP, MP, and LP (Table 3). Most of the

Table 4. Abnormal thermal patterns in patients

\begin{tabular}{lcc}
\hline \multirow{2}{*}{\multicolumn{1}{c}{ Region }} & \multicolumn{2}{c}{ No. of abnormal case (\%) } \\
\cline { 2 - 3 } & Hyperthermia & Hyopthermia \\
\hline Low back & $2(2)$ & $19(19)$ \\
Buttock & $2(2)$ & $34(34)$ \\
Thigh & $3(3)$ & $36(36)$ \\
Knee & $2(2)$ & $36(36)$ \\
Lower leg & $4(4)$ & $59(58)$ \\
Ankle & $4(4)$ & $59(58)$ \\
Foot & $4(4)$ & $51(50)$ \\
Plantar surface & $4(4)$ & $50(50)$ \\
\hline At least one region & $7(7)$ & $72(71)$ \\
\hline
\end{tabular}

patients presenting an abnormal thermal pattern on the involved side were hypothermic $(71 \%)$ rather than hyperthermic (7\%) (Table 4). The most commonly involved regions were lower leg and knee (58\%), and foot and plantar surface $(50 \%)$.

Correlations between DITI and clinical, MRI, or electrophysiological findings

When comparing the DITI findings with the clinical findings, motor weakness was related to abnormal $\Delta \mathrm{T}$ on the low back (sensitivity, 66.7\%); the patients who had L5 myotome weakness showed abnormal $\Delta \mathrm{T}$ on the buttock (sensitivity, 61.1\%), and those with S1 myotome weakness showed abnormal $\Delta \mathrm{T}$ on the lateral knee and the buttock (sensitivity, $50.0 \%$ and $55.6 \%$, respectively) (Table 5). Neither age, gender, symptom duration, nor any of the other symptoms or physical findings including radiating pain, sensory changes and decrement of deeptendon reflex, was correlated with $\Delta \mathrm{T}$ in the 30 ROIs. The patients who presented lateral-type disc herniation in the lumbosacral region showed abnormal $\Delta \mathrm{T}$ on the heel and posterior thigh (sensitivity, $91.7 \%$ and $87.5 \%$, respectively), and those with abnormal needle electromyography (EMG) findings showed abnormal $\Delta \mathrm{T}$ on the low back (sensitivity, 63.6\%) (Table 5). Neither central-type disc

Table 5. Relationships between DITI findings and clinical, MRI or electrophysiological findings

\begin{tabular}{|c|c|c|c|c|c|c|}
\hline \multirow{2}{*}{ Parameter } & \multirow{2}{*}{ Related ROI } & \multirow{2}{*}{$\begin{array}{c}\text { Sensitivity } \\
\text { (\%) }\end{array}$} & \multirow{2}{*}{$\begin{array}{c}\text { Specificity } \\
\text { (\%) }\end{array}$} & \multicolumn{2}{|c|}{ Predictive value (\%) } & \multirow{2}{*}{ p-value } \\
\hline & & & & Positive & Negative & \\
\hline \multicolumn{7}{|l|}{ Clinical findings } \\
\hline Lower-extremity pain & None & - & - & - & - & - \\
\hline Sensory changes & None & - & - & - & - & - \\
\hline Motor weakness & LB & 66.7 & 61.5 & 28.6 & 88.9 & 0.047 \\
\hline L5 myotome & BT & 61.1 & 65.6 & 34.4 & 85.1 & 0.043 \\
\hline \multirow[t]{2}{*}{ S1 myotome } & LK & 50.0 & 80.0 & 38.1 & 86.7 & 0.014 \\
\hline & BT & 55.6 & 83.6 & 50.0 & 86.4 & 0.001 \\
\hline Deep tendon reflex & None & - & - & - & - & - \\
\hline \multicolumn{7}{|l|}{ MRI findings } \\
\hline Central type & None & - & - & - & - & - \\
\hline \multirow[t]{2}{*}{ Lateral type } & $\mathrm{HE}$ & 91.7 & 62.5 & 47.8 & 95.2 & 0.001 \\
\hline & $\mathrm{PT}$ & 87.5 & 50.8 & 19.4 & 96.8 & 0.041 \\
\hline \multicolumn{7}{|l|}{ Electrodiagnosis } \\
\hline Needle EMG & LB & 63.6 & 77.0 & 33.3 & 92.2 & 0.006 \\
\hline All abnormal cases & None & - & - & - & - & - \\
\hline
\end{tabular}


Table 6. Relationships between abnormal thermal pattern and lumbosacral disc herniation of lateral type

\begin{tabular}{|lccccc}
\cline { 1 - 1 } \multicolumn{1}{c}{ Region } & \multirow{2}{*}{ Sensitivity (\%) } & Specificity (\%) & \multicolumn{2}{c}{ Predictive value (\%) } & \multirow{2}{*}{ p-value } \\
\cline { 1 - 1 } & & - & Positive & Negative & \\
\hline Low back & - & - & - & - & - \\
Buttock & 66.7 & 85.7 & 87.5 & 63.1 & 0.002 \\
\hline Thigh & 64.5 & 85.7 & 90.9 & 52.2 & 0.003 \\
\hline Knee & 64.5 & 85.7 & 90.9 & 52.2 & 0.003 \\
\hline Lower leg & 70.5 & 85.7 & 93.9 & 48.0 & 0.000 \\
\hline Ankle & 65.2 & 85.7 & 93.8 & 42.9 & 0.002 \\
\hline Foot & 63.4 & 85.7 & 92.9 & 44.4 & 0.002 \\
\hline Plantar surface & 65.9 & 85.7 & 93.1 & 46.2 & 0.001 \\
\hline At least one region & 64.8 & 80.0 & 92.1 & 38.7 & 0.003 \\
\hline
\end{tabular}

herniation nor electrophysiological abnormalities (except needle EMG) were related to $\Delta \mathrm{T}$ in the 30 ROIs.

Abnormal thermal patterns in all seven regions from the low back to the lower extremities were related to lateral-type disc herniation for the $63.4 \%-70.5 \%$ sensitivity range (Table 6). However, those patterns did not differ according to level of disc herniation.

\section{DISCUSSION}

Skin is a dynamic membrane regulating the interaction between the body and its environment, and is crucial for the regulation of body temperature [12]. Skin temperature changes continuously according to the blood circulation to the skin, and can be detected easily using infrared thermography in the clinical setting. For more than 20 years, a considerable number of studies have sought to determine the relationship between skin temperature and low back pain [15], radiating pain [16] or lumbar disc herniation [17], but have failed to do so. However, many of those investigations were flawed. Specifically, they did not divide their MRI findings into central and lateral types; the numbers of cases examined were too small (less than 50); and the focus on low back pain was faulty as this is not a representative symptom of lumbosacral radiculopathy; moreover, they did not check the skin temperature over the entire back and lower-extremity areas, which is essential for accurate analysis of thermal patterns.

In the present study, we were able to correlate lateraltype herniation, abnormal needle EMG findings and motor weakness to abnormal $\Delta \mathrm{T}$ in some ROIs $(\mathrm{p}<0.05)$. Lateral-type disc herniation is more likely to compress the root and cause denervation of innervated muscles, which leads to muscle atrophy. In cases of central-type disc herniation, in contrast, root compression and concomitant muscle denervation are not common, and therefore, skin temperature typically is unchanged.

In two of our previous studies, we found that skin temperature following shoulder impingement syndrome and unilateral ulnar neuropathy had decreased more on the involved side than on the uninvolved side; we determined such hypothermia might be due to muscle atrophy following immobilization or denervation of the involved muscles $[18,19]$. And in another study, we discovered that multifidus muscle atrophy was prominent in patients with severe lumbosacral radiculopathy [22]. Therefore, muscle atrophy in the low back and lower extremities (posterior tibia and heel) might be the major cause of lowered involved-side skin temperature following lumbosacral radiculopathy (Tables 5,6 ).

However, in this study, abnormal $\Delta \mathrm{T}$ or thermal patterns did not follow the dermatome or myotome, consistent with the findings of previous studies concerning cervical or lumbosacral radiculopathies [23,24]. The blood supply to the skin on the back and lower extremities is quite different from the sensory and motor nerves distribution in the same region, and, like the dermatome and myotome, is difficult to localize. Some of the patients (7\%) showed a hyperthermic pattern on the involved side, which might be explained by autonomic dysfunction following peripheral nerve injury including changes of the sympathetic tone and norepinephrine synthesis [25], although the exact mechanism of hyperthermia following lumbosacral radiculopathy is unknown.

The relationship between pain and skin temperature 
change remains unclear [26]. In our study, neither the existence of radiating lower-extremity pain nor pain severity was related to skin temperature change.

There are many factors influencing skin temperature, including emotional stress and depression, which can affect autonomic dysfunction [27], as well as the circadian rhythm, which results in diurnal variation of body temperature [28]. Therefore, a drawback of our study is that we did not screen our subjects for any psychological problems; relatedly, the time at which the DITI was performed was not the same for all patients and controls. Another problematic aspect of our study is that the patients were, on average, older than the controls, which might have resulted in lower skin temperatures among the patients, given that muscle mass normally decreases with age [29]. However, this factor was probably mitigated by the fact that we analyzed only the temperature difference between the two sides of the back and the lower extremities (not the absolute skin temperature value); therefore the psychological, circadian rhythm, and aging effects might not have influenced our results after all.

Another limitation of this study is that we did not check any available surgical findings although surgical findings are the gold standard for confirmation of lumbosacral radiculopathy in patients who have undergone surgery following DITI. Clinical, MRI, and electrophysiological findings do not always correlate with each other [3], and such an unclear standard for lumbosacral radiculopathy might have limited the value of any interpretive analysis of skin temperature changes.

Even though we found some positive DITI findings in patients with lumbosacral radiculopathy, DITI cannot be a definite diagnostic tool for evaluation of lumbosacral radiculopathy. As mentioned earlier, the abnormal thermal patterns cannot be divided into lumbosacral levels. And the low sensitivity (less than 71\%) makes DITI unacceptable as a screening tool for detection of lumbosacral radiculopathy. MRI and electrophysiologic testing, moreover, are still more useful methods for evaluation of the level and severity of radiculopathy than is DITI.

In conclusion, the present study attempted to relate skin temperature change following lumbosacral radiculopathy to some clinical and MRI findings suggestive of muscle atrophy. DITI, though with limitations, might be used as a complementary tool for the diagnosis of unilateral lumbosacral radiculopathy.

\section{CONFLICT OF INTEREST}

No potential conflict of interest relevant to this article was reported.

\section{ACKNOWLEDGMENTS}

This research was supported by the Basic Science Research Program through the National Research Foundation of Korea funded by the Ministry of Education, Science and Technology (No. 2010-0021155).

\section{REFERENCES}

1. van der Windt DA, Simons E, Riphagen II, Ammendolia C, Verhagen AP, Laslett M, et al. Physical examination for lumbar radiculopathy due to disc herniation in patients with low-back pain. Cochrane Database Syst Rev 2010;(1):CD007431.

2. Lauder TD. Physical examination signs, clinical symptoms, and their relationship to electrodiagnostic findings and the presence of radiculopathy. Phys Med Rehabil Clin N Am 2002;13:451-67.

3. Modic MT, Obuchowski NA, Ross JS, Brant-Zawadzki MN, Grooff PN, Mazanec DJ, et al. Acute low back pain and radiculopathy: MR imaging findings and their prognostic role and effect on outcome. Radiology 2005;237:597-604.

4. Carragee EJ, Alamin TF, Miller JL, Carragee JM. Discographic, MRI and psychosocial determinants of low back pain disability and remission: a prospective study in subjects with benign persistent back pain. Spine J 2005;5:24-35.

5. Ash LM, Modic MT, Obuchowski NA, Ross JS, BrantZawadzki MN, Grooff PN. Effects of diagnostic information, per se, on patient outcomes in acute radiculopathy and low back pain. AJNR Am J Neuroradiol 2008;29:1098-103.

6. Wassenaar M, van Rijn RM, van Tulder MW, Verhagen AP, van der Windt DA, Koes BW, et al. Magnetic resonance imaging for diagnosing lumbar spinal pathology in adult patients with low back pain or sciatica: a diagnostic systematic review. Eur Spine J 2012;21:2207.

7. Jensen MC, Brant-Zawadzki MN, Obuchowski N, Modic MT, Malkasian D, Ross JS. Magnetic resonance 
imaging of the lumbar spine in people without back pain. N Engl J Med 1994;331:69-73.

8. Fisher MA. Electrophysiology of radiculopathies. Clin Neurophysiol 2002;113:317-35.

9. Wilbourn AJ, Aminoff MJ. AAEM minimonograph 32: the electrodiagnostic examination in patients with radiculopathies. American Association of Electrodiagnostic Medicine. Muscle Nerve 1998;21:1612-31.

10. Edeiken J, Shaber G. Thermography: a reevaluation. Skeletal Radiol 1986;15:545-8.

11. Krumova EK, Frettloh J, Klauenberg S, Richter H, Wasner G, Maier C. Long-term skin temperature measurements: a practical diagnostic tool in complex regional pain syndrome. Pain 2008;140:8-22.

12. Ring F. Thermal imaging today and its relevance to diabetes. J Diabetes Sci Technol 2010;4:857-62.

13. Zhang HY, Kim YS, Cho YE. Thermatomal changes in cervical disc herniations. Yonsei Med J 1999;40:40112.

14. Ben-Eliyahu DJ. Thermographic imaging of pathoneurophysiology due to cervical disc herniation. J Manipulative Physiol Ther 1989;12:482-90.

15. Leclaire R, Esdaile JM, Jequier JC, Hanley JA, Rossignol M, Bourdouxhe M. Diagnostic accuracy of technologies used in low back pain assessment. Thermography, triaxial dynamometry, spinoscopy, and clinical examination. Spine (Phila Pa 1976) 1996;21:1325-30.

16. Lebkowski WJ, Kozłowski A, Lyson T. The superficial skin temperature of low extremities in patients with sciatica. Rocz Akad Med Bialymst 2001;46:153-7.

17. Tuzgen S, Dursun S, Abuzayed B. Electrical skin resistance and thermal findings in patients with lumbar disc herniation. J Clin Neurophysiol 2010;27:303-7.

18. Park JY, Hyun JK, Seo JB. The effectiveness of digital infrared thermographic imaging in patients with shoulder impingement syndrome. J Shoulder Elbow Surg 2007;16:548-54.

19. Jang YY, Byun SH, Lee SJ, Kim TU, Hyun JK. Clinical significance of digital infrared thermal imaging in unilateral ulnar neuropathy. J Korean Assoc EMG Electrodiagn Med 2009;11:78-84.

20. Tans RJ, Vredeveld JW. Somatosensory evoked potentials (cutaneous nerve stimulation) and electromyography in lumbosacral radiculopathy. Clin Neurol Neurosurg 1992;94:15-7.

21. Han TR, Kim JH, Paik NJ. A study on new diagnostic criteria of H reflex. Electromyogr Clin Neurophysiol 1997;37:241-50.

22. Hyun JK, Lee JY, Lee SJ, Jeon JY. Asymmetric atrophy of multifidus muscle in patients with unilateral lumbosacral radiculopathy. Spine (Phila Pa 1976) 2007;32:E598-602.

23. So YT, Olney RK, Aminoff MJ. A comparison of thermography and electromyography in the diagnosis of cervical radiculopathy. Muscle Nerve 1990;13:1032-6.

24. So YT, Aminoff MJ, Olney RK. The role of thermography in the evaluation of lumbosacral radiculopathy. Neurology 1989;39:1154-8.

25. Wakisaka S, Kajander KC, Bennett GJ. Abnormal skin temperature and abnormal sympathetic vasomotor innervation in an experimental painful peripheral neuropathy. Pain 1991;46:299-313.

26. Besson M, Brook P, Chizh BA, Pickering AE. Tactile allodynia in patients with postherpetic neuralgia: lack of change in skin blood flow upon dynamic stimulation. Pain 2005;117:154-61.

27. Lin HP, Lin HY, Lin WL, Huang AC. Effects of stress, depression, and their interaction on heart rate, skin conductance, finger temperature, and respiratory rate: sympathetic-parasympathetic hypothesis of stress and depression. J Clin Psychol 2011;67:1080-91.

28. Krauchi K, Wirz-Justice A. Circadian rhythm of heat production, heart rate, and skin and core temperature under unmasking conditions in men. Am J Physiol 1994;267(3 Pt 2):R819-29.

29. Thompson LV. Effects of age and training on skeletal muscle physiology and performance. Phys Ther 1994;74:71-81. 